\title{
Espacio y Política: Por una Teoría Política Situada*
}

\author{
Heriberto Cairo
}

Professor titular da Facultad de Ciencias Políticas y Sociología, da Universidad Complutense de Madrid, Espanha

\section{INTRODUCCIÓN}

I a política y el espacio, a priori, parecen constituir los objetos centraL les de dos saberes o, si se prefiere, disciplinas científicas (la Ciencia Política y la Geografía, respectivamente), que en la actualidad están plenamente establecidas y diferenciadas. Pero las cosas muchas veces no son lo que aparentan, recordemos que etimológicamente la palabra "política" viene del griego polis, que era la denominación de un espacio geográfico (la ciudad), de modo que, en sus orígenes, el saber sobre lo político se confunde en parte con el saber sobre los espacios políticos. Pero no ha sido esa la posición que ha adoptado, en general, la ciencia política dominante: los estudios sobre los fenómenos políticos parecerían producirse en un mundo semejante a una bola de billar, en el que los emplazamientos pudieran intercambiarse sin que afectase al resultado final ya que no existirían diferencias o, en el extremo opuesto, estarían condenados a producirse de determinado modo debido a las raíces espaciales que determinarían la conducta política. Gran parte de esta discusión ha sido conocida en Geografía como el debate entre deterministas y posibilistas, pero es un debate que enmascara una co-

\footnotetext{
* Agradezco los comentarios a este artículo de Breno Bringel, María Lois y dos evaluadores anónimos, que han contribuido en buena medida a su mejora.
}

DADOS - Revista de Ciências Sociais, Rio de Janeiro, vol. 56, nํ4, 2013, pp. 769 a 802. 


\section{Heriberto Cairo}

munión más íntima entre las partes respecto a las asunciones primordiales.

En este trabajo, la revisión de la concepción del espacio, implícita o explícita, en la teoría política moderna y las transformaciones postmodernas forma parte del estudio más amplio de los cambios recientes en la conceptualización del territorio y la soberanía de los Estados. No se trata de hacer una historia de las ideas políticas, es decir, de trazar la evolución del concepto a través de los escritos políticos de autores más o menos relevantes, ni siquiera de trazar una genealogía de la conceptualización moderna del espacio político, sino sólo de mostrar, deconstruir si se quiere, las características de la espacialidad de la política moderna, a fin de entender el carácter contingente de los conceptos mencionados.

El período de indagación se inicia con la "revolución espacial", por utilizar el término de Carl Schmitt (1942 [1952: 66 y ss.]), que se produce en los siglos XVI y XVII. La noción de "revolución espacial" alude a los cambios radicales que se producen en ciertos momentos en la forma de ver el mundo, en la forma de autoubicarse y ordenar los hechos políticos y sociales, los cuales implican el surgimiento de "un mundo absolutamente nuevo", de una "conciencia colectiva" inédita. Pero lo que es más importante es que "todo cambio o variación notable de la imagen de la tierra va unido a cambios políticos universales, a una nueva distribución del globo" (Schmitt, 1942 [1952:71]): las nuevas formas de vida política - por ejemplo, las administraciones centralizadas - que surgen en Europa occidental, convirtiéndose en precursoras de los Estados modernos, realizan trasformaciones hacia fuera, imponiendo un nuevo nomos del mundo, y hacia dentro, homogeneizando el territorio del Estado. Exploraremos después los presupuestos y los puntos de partida respecto a la relación entre política y espacio de la teoría política liberal. Luego expondremos la crítica posmoderna y sus "raíces" teóricas.

En la segunda parte intentaremos mostrar algunos de los elementos para desarrollar una teoría política situada, en la que el espacio sea consciente y explícitamente considerado, discutiendo en particular las relaciones entre discurso, estructura y agencia a la hora de abordar el estudio de la cuestión.

Por fin, se tratará de entender, a la luz de lo expuesto, el interés de la interdisciplinaridad y de la transdisciplinaridad a la hora de construir 
herramientas analíticas poderosas. ¿Conduce a mejores herramientas el diálogo interdisciplinar o es meramente una conversación, en el mejor de los casos, erudita? ¿Situarse en las periferias disciplinares permite tener una visión de conjunto mejor que si se está en el mainstream? ¿Las intersecciones disciplinares arrojan nuevas luces o son una rémora?

\section{CONCEPCIONES DEL ESPACIO EN LA TEORÍA POLÍTICA}

Si es difícil llegar a un acuerdo entre los estudiosos de la política sobre qué es la política, resulta mucho más complicado establecer de común acuerdo cuáles son las relaciones entre lo político y lo espacial. A una definición autorizada de lo político se puede responder con otra, y a una afirmación de la radical - por su fundamento - relación entre lo espacial y lo político puede contestarse con la afirmación diametralmente opuesta. Entendemos que esencialmente se han dado tres formas de relacionar lo espacial y lo político desde el Renacimiento: a) Casi intuitivamente se suele tender a considerar lo espacial como simplemente el escenario de la actividad política, ya que ésta, como toda actividad humana, se produce sobre un soporte ambiental; b) no obstante, como veremos, ésta es una concepción muy simplista, ya que en la modernidad la actividad política no se ejerce respecto a cualquier porción del espacio - terrestre o cósmico -, sino que se encuentra limitada en su alcance, en otras palabras, está territorializada. Ésta será nuestra segunda vía de aproximación a las relaciones existentes entre lo espacial y lo político; c) pero se produce una creciente problematización de ambas concepciones de la relación que nos ocupa: por un lado, cada vez es más difícil pensar en el espacio como algo neutral e inmutable y, por otro, las actividades desterritorializadas se presentan con mayor nitidez y frecuencia. La ubicación, el emplazamiento espacio-temporal, las redes espaciales y sus nodos pasan a un primer plano en las perspectivas postmodernas sobre la política.

\section{A) La Actividad Política Tiene un Escenario Geográfico}

En buena medida la indagación debería empezar por quien suele asociarse a la nueva concepción de la política, que indudablemente está ligada a la revolución espacial del Renacimiento a la que aludía Schmitt: Nicolás Maquiavelo. Este autor es considerado el precursor fundamental de la corriente realista en las relaciones internacionales y la política de poder del Estado moderno encontraría su primer arquetipo en 


\section{Heriberto Cairo}

su obra El Príncipe, de la que suelen partir los que piensan el mundo como un puzzle eterno de Estados en permanente competición.

Aunque desde una perspectiva radicalmente diferente a la aludida, R.B.J. Walker (1989) también interpreta la obra de Maquiavelo como trascendental, pero que hay que entender dentro de su contingencia histórica. Maquiavelo habría hecho un esfuerzo, central para la modernidad, de, por un lado, “articular una concepción de la comunidad política en el tiempo" frente a los universales de la teoría escolástica, y, por otro, de situar al Estado en un espacio "dentro del que es posible aspirar a la virtú, aunque sólo sea por un corto periodo" (Walker, 1989:42). Deberíamos entonces a Maquiavelo el poder situar al Estado, a la comunidad política, en el contexto de un espacio absoluto euclidiano-galileico que sustituía las complejas y solapadas jerarquías espaciales medievales.

Pero es mejor acudir a otras obras para ver con más nitidez la que decíamos que era la concepción más simple de la relación entre lo espacial y lo político, que es considerar que la actividad política se desarrolla en un escenario geográfico. Veamos un ejemplo paradigmático en uno de los textos capitales del que para algunos fue el fundador de la moderna Ciencia Política, Tocqueville:

Aun cuando el vasto país que acabo de describir haya estado habitado por numerosas tribus indígenas, se puede decir con justicia que en la época del descubrimiento no era todavía más que un desierto. Los indios lo ocupaban, pero no lo poseían. [...] Sus implacables prejuicios, sus pasiones indómitas, sus vicios y, quizá, sobre todo, sus virtudes salvajes, les predestinaban a una destrucción inevitable. [...] La Providencia, al situarles en medio de las riquezas del Nuevo Mundo, parece no haberles dado más que un corto usufructo; en cierto sentido, no estaban allí más que esperando. Estas costas, tan bien preparadas para el comercio y la industria, estos ríos tan profundos, este inagotable valle del Mississippi, este continente entero, parecían entonces como la cuna, todavía vacía, de una gran nación. Era allí donde los hombres civilizados tenían que ensayar la construcción de la sociedad sobre fundamentos nuevos (el énfasis es mío) (1840 [1971:27]).

El texto seleccionado, ciertamente, plantea varias cuestiones, no sólo respecto a la geopolítica sino a la biopolítica ${ }^{1}$ : la distinción entre hombres civilizados y salvajes no es mero ejercicio de identidad/diferenciación, sino que implica una caracterización jerárquica de las vidas de 
los grupos humanos implicados. Pero, en lo que a nuestro inmediato argumento afecta, lo sustancial de esta concepción es la idea de que es necesario un soporte físico para el desarrollo de la actividad humana. En este sentido, es secundario si se concibe el soporte como neutral o determinante de conductas. Tocqueville, en la línea inicial de la tradición política liberal, lo consideraba neutral, sus potencialidades eran las mismas para dos grupos humanos (los indios y los "civilizados"), pero sólo podían ser explotadas por los segundos, cuyas virtudes eran superiores.

Otros pensadores políticos, de los que Montesquieu puede ser representativo, concibieron el espacio como determinante de las conductas políticas humanas. Este autor se preocupó toda su vida de las relaciones entre la diferenciación física de la superficie del planeta y la variedad de caracteres de los seres humanos y de las organizaciones políticas, y quizá sea uno de los autores que muestra más nítidamente los rasgos del determinismo ambiental respecto a la política que caracteriza a la mayor parte de las reflexiones geográfico-políticas premodernas. En L'Esprit des Lois (1748) concede gran importancia a diversas influencias del medio físico local, especialmente el clima, como determinantes del comportamiento de los pueblos. En diversos pasajes de los libros XIV al XVII de la obra se menciona esta circunstancia; la diferencia entre los climas de los países del Norte y aquellos de los del Sur es la que parece llamar más su atención. Sus reflexiones, claramente etnocéntricas, intentan explicar una pretendida superioridad de los pueblos nórdicos:

Hay en los climas del Norte pueblos de pocos vicios, bastantes virtudes y mucha sinceridad y franqueza. Aproximaos a los países del Sur, y creeréis que cada paso os aleja de la moralidad: las pasiones más vivas multiplicarán la delincuencia. Ya en la zona templada son los pueblos inconstantes en sus usos, en sus vicios, hasta en sus virtudes, porque el clima tampoco tiene fijeza (Montesquieu, 1748: Libro XIV, capítulo II [1964:163]).

La determinación del clima sobre el comportamiento de los pueblos se produce a través del condicionamiento de los cuerpos de las personas:

El calor del clima puede ser tan extremado, que el cuerpo del hombre desfallezca. Perdida la fuerza física, el abatimiento se comunicará insensiblemente al ánimo; nada interesará, no se pensará en empresas nobles, no habrá sentimientos generosos; todas las inclinaciones serán pa- 
sivas, no habrá felicidad fuera de la pereza y la inacción, los castigos causarán menos dolor que el trabajo, la servidumbre será menos soportable que la fuerza de voluntad necesaria para manejarse uno por sí mismo (1748: Libro XIV, capítulo II [1964:164]).

Y una vez establecidas las diferencias "naturales" entre los hombres y los pueblos es fácil concluir que las leyes han de ser diferentes en cada clima: "Las distintas necesidades en los diversos climas han formado las diferentes maneras de vivir; y las diferentes maneras de vivir han originado diversidad de leyes; no pueden éstas ser las mismas para la nación en que los hombres se comuniquen mucho, que para un pueblo en que no se comuniquen" (1748: Libro XIV, capítulo X [1964:169].

No obstante, sería injusto no señalar que para Montesquieu la influencia de la naturaleza y el clima era una más entre otras y que actuaba principalmente "sobre los salvajes". Para Montesquieu se trataría de estudiar las relaciones de los grupos humanos con el medio, no las relaciones entre seres humanos en el espacio. Pero tanto en su caso como en el Tocqueville, el espacio está separado radicalmente de la acción humana, la antecede, es independiente de ella. En definitiva, esta concepción de la actividad política como algo que tiene lugar en el espacio establece una fundamental diferencia ontológica entre ambas categorías.

A pesar de ello, para la mayor parte de las filosofías racionalistas y evolucionistas el espacio no era una categoría relevante para el análisis de lo social, por lo que ha estado relativamente ausente de las reflexiones de los pensadores políticos, desde Condorcet a Marx.

\section{B) La Actividad Política Está Territorializada}

Dahl (1970), en uno de los textos ya clásicos de la Ciencia Política, marca una pauta interesante para nuestra tarea de buscar las relaciones entre lo político y lo espacial al analizar las posiciones mantenidas por Aristóteles, Weber y Lasswell sobre la naturaleza de la política. Ellos, como casi todos los politólogos, según Dahl, estarían de acuerdo en que las relaciones políticas "implican poder, mando o autoridad" (1970 [1976:11]). Pero Weber y Aristóteles incorporaban características adicionales a la definición de la naturaleza de lo político; el primero puso énfasis en la raíz territorial de toda relación política y el segundo incluía en lo político "las relaciones en asociaciones capaces de mantenerse por sí solas" (Dahl, 1970 [1976:11]). Por lo tanto, existiría un área de intersección, que sería el "mínimo común denominador" de las tres 
posiciones. Y en ella, no por casualidad, se conjugan elementos obligados de cualquier definición de la naturaleza de la política, entre los que se encuentran, significativamente: el poder y la territorialidad.

La concepción weberiana de la asociación política se relaciona con la noción de dominación. Para Weber, "poder significa la probabilidad de imponer la propia voluntad dentro de una relación social" (1956 [1964:43]), pero las situaciones en las que una persona puede imponer su voluntad son tantas y tan variadas que le conducen a calificar este concepto de "amorfo" y desarrollar el de dominación, que considera como "la probabilidad de encontrar obediencia a un mandato de determinado contenido entre personas dadas" (1956 [1964:43]). Las asociaciones, que son relaciones sociales "con una regulación limitadora hacia fuera cuando el mantenimiento de su orden está garantizado por la conducta de determinados hombres destinada en especial a ese propósito" (Weber, 1956 [1964:39]), son de dominación cuando sus miembros están sometidos a relaciones de dominación en virtud del orden vigente. Pero las asociaciones de dominación son asociaciones políticas sólo "cuando y en la medida en que su existencia y la validez de sus ordenaciones, dentro de un ámbito geográfico determinado, estén garantizados de un modo continuo por la amenaza y aplicación de la fuerza física por parte de su cuadro administrativo" (Weber, 1956 [1964:43]). Vemos entonces que uno de los elementos fundamentales de una asociación política es la relación territorial, es decir, que las ordenaciones de la asociación tienen una validez territorial, y, en este sentido, las asociaciones políticas son también asociaciones territoriales. Independientemente de las características del territorio, que no siempre han sido las que tiene en las asociaciones políticas modernas (los Estados), Weber es extremadamente claro:

Entendemos por comunidad política aquella cuya acción consiste en que los partícipes se reservan la dominación ordenada de un "ámbito" [geográfico] (no necesariamente constante en absoluto y delimitado con fijeza, pero sí delimitable de algún modo) y de la acción de los hombres situados en él de un modo permanente o sólo provisional, teniendo preparada para el caso la fuerza física, normalmente armada (1956 [1964:661]).

Y otro de los elementos fundamentales es el empleo de la violencia física. Y en eso nos reafirmamos si recordamos la famosa definición del Estado que da en su conferencia sobre La política como profesión: "El Estado es aquella comunidad humana que, dentro de un determinado 
territorio - el 'territorio' es un elemento distintivo -, reclama para sí (con éxito) el monopolio de la violencia física legítima" (Weber, 1919 [2001:94]).

Si la guerra es la expresión máxima del "monopolio de la violencia física legítima", la conjunción entre guerra y territorio se encuentra en el centro de la definición weberiana del Estado moderno; constituyen, por tanto, el vortex de las prácticas estatales. La guerra sería privilegio del Estado, y el "territorio" del Estado sería el ámbito de referencia de la misma.

Mann (1993:55) sostiene que hay tres estadios que Weber distingue en el desarrollo institucional de lo político: el poder político, el Estado y el Estado moderno. Y, ya desde el primer estadio, el poder político sería esencialmente territorial: sólo se puede imponer en un área territorial dada. Según él, en el Estado-nación, que evidentemente es la forma de organización política que se ha generalizado en la economía-mundo capitalista, el uso novedoso de la territorialidad se ha concretado especialmente en tres aspectos: la creación de un concepto de "espacio vaciable" - es decir, un espacio físico separado conceptualmente de los constructos sociales o económicos o de las cosas -, la creación de las burocracias modernas - cuyas actividades tienen límites explícitamente territoriales - y el oscurecimiento de las fuentes del poder social.

Y es más, el secreto de la perdurabilidad del Estado se encuentra, según Mann (1984), en la eficacia² de los "servidores" del Estado - mayor que la que podrían tener personas vinculadas a otro tipo de organizaciones - en el ejercicio de cuatro tareas: el mantenimiento del orden interior, la defensa / agresión militar contra enemigos externos, el mantenimiento de las infraestructuras de comunicación y la redistribución económica. Estas tareas se llevan a cabo sobre una base territorial, y esto es lo que distingue al Estado de las agrupaciones de poder en la sociedad civil: "El Estado es, de hecho, un lugar [...] Las principales formas del poder autónomo estatal derivarán de este atributo distintivo del Estado" (Mann, 1984 [1991:32]).

Carl Schmitt daría un paso más. En su teoría política el espacio, y en particular el espacio terrestre, desempeña un papel fundamental. Tiene por un lado, un carácter vital para la supervivencia de los seres humanos, pero sobre todo es constitutivo de todo derecho y de la comunidad política. Y ello es así porque "la toma de la tierra [...] es el primer título jurídico en el que se basa todo derecho ulterior [...] La historia de 
todo pueblo que se ha hecho sedentario, de toda comunidad y de todo imperio se inicia, pues, en cualquier forma con el acto constitutivo de una toma de la tierra" (Schmitt, 1950 [2002:7-10]). La acción política se encontraría entonces asociada al territorio, estaría territorializada, y el establecimiento de los límites de ese territorio, la "toma de la tierra" schmittiana, estaría necesariamente asociado originalmente al empleo de la violencia de uno u otro tipo.

Los practicantes de la Geopolitik, ligados al nacionalsocialismo alemán, de entre los que destaca el general Karl Haushofer, llevaron esta idea hasta sus últimas consecuencias: si el Estado es ante todo territorio - es un "organismo territorial", según su formulación - la acción política sólo es efectiva si tiene un "sentido de espacio" (Raumsinn) (ver, por ejemplo, Haushofer, 1927 [2012]), es decir, si comprende los constreñimientos del medio y se adapta a ellos.

Pero la concepción de la asociación política en Weber, común a casi todos los enfoques modernistas de la Ciencia Política, presenta dos problemas: por un lado, no siempre se produciría una coincidencia entre poder político y poder militar, y por otro, es dudosa la universalidad del carácter territorial de la asociación política. En relación con la primera crítica, cabe sostener, como lo hace Giddens, que

el aspecto político de las organizaciones se refiere a su capacidad de disponer ordenadamente los "recursos de autoridad" o lo que denomino poder administrativo. Todas las organizaciones tienen características políticas, pero sólo en el caso de los Estados implican la consolidación del poder militar asociado con el control de los medios de violencia en una serie de territorios (1987:19-20; traducción propia).

Respecto al enunciado universal del carácter territorial de toda asociación política, choca con evidencias empíricas contrarias, especialmente en el África negra. Allí, según estudiosos del caso, como Diagne (1981 [1983]), están disociadas la jefatura territorial y la política, y la preeminencia de la última sobre la primera es resultado de un proceso evolutivo ${ }^{3}$. Ciertamente esto introduciría un sesgo etnocéntrico en la argumentación weberiana, pero no anularía sus consecuencias para el mundo actual dada la universalización del modelo político occidental.

Aunque el problema principal de la argumentación modernista es que se basa precisamente en la asunción implícita de que la política es algo que está restringido al interior de la comunidad política, y ésta sólo 


\section{Heriberto Cairo}

puede ocurrir dentro de los límites seguros de los Estados soberanos. De este modo, como señalan Walker y Mendlovitz (1990: 4), "la historia del pensamiento político occidental ha sido escrita como un cuento con dos tradiciones": una que festeja la polis - y subsiguientemente el Estado -, en cuanto base segura de la comunidad política, y otra que advierte de la ausencia de comunidad política más allá del Estado, que lleva en última instancia a la guerra o a la preparación para la misma.

Si la libertad y el progreso sólo se pueden dar en un tipo semejante de comunidad política, "el principio de la soberanía estatal formaliza una respuesta específica sobre quiénes somos en tanto que seres políticos" (Walker y Mendlovitz, 1990:5). Así, seríamos ciudadanos antes que seres humanos y las reivindicaciones relacionadas con el primer carácter (nacionalismo, seguridad nacional, etc.) tienen prioridad sobre las consustanciales con el segundo (derechos humanos universales, ética universal de tolerancia, etc.).

En fin, si la Ciencia Política modernista no es una ciencia del Estado, sí es, al menos, una ciencia estadocéntrica, no en el sentido de que estudie sólo las instituciones y actividades estatales - concepción superada tempranamente - sino porque las unidades de análisis son los Estados. Esta forma de considerar las relaciones entre espacio y política parte de una concepción cartesiana de la categoría espacio: la extensión es un atributo de todas las cosas. Evidentemente establece una relación entre el atributo y su predicado, pero tiende a concebirlos como autónomos (Lévy, 1994).

\section{C) La Actividad Política Está Constituida Espacialmente}

La consideración del espacio, ya sea como escenario independiente del ser humano, ya sea como contenedor de la actividad política, comenzó a ser cuestionada en las Ciencias Sociales ${ }^{4}$ fundamentalmente partir de la obra de dos autores clave en el tránsito de la modernidad a la postmodernidad: Michel Foucault y Henri Lefebvre. Aunque no pueden obviarse las conexiones con la obra de Heidegger y anteriormente de Nietzsche (Elden, 2001).

La categoría "espacio" tiene una importancia fundamental para el análisis de las relaciones de poder de Foucault y choca frontalmente con las consideraciones prevalecientes hasta el momento. Para Foucault (1976) las relaciones de poder son relaciones espaciales; el espacio no 
es independiente de esas relaciones, sino que es precisamente esa relación.

Este hecho es central en la argumentación general de Foucault, que gira en torno a una específica concepción relacional del poder. El "poder" no se puede conquistar, mantener o perder, eso supondría independizarlo de las relaciones sociales, que entonces se podrían en teoría constituir al margen del poder. Implicaría poco menos que entenderlo como un "botín" que genera guerras por su captura. Pero la humanidad, para Foucault, es "efecto e instrumento de relaciones de poder complejas, cuerpos y fuerzas sometidos por dispositivos de 'encarcelamiento' múltiples, objetos para discursos que son ellos mismos elementos de esta estrategia" (el énfasis es mío) (1975 [1976:314]).

Los innovadores análisis de Lefebvre acerca del carácter relativo de la concepción del espacio y de las prácticas espaciales en cada sociedad se resumen en la que fue una provocativa proposición: "El espacio (social) es un producto (social)" (Lefebvre, 1974:35). Los estudios geográfico-políticos de carácter crítico desarrollaron a partir de entonces una nueva forma de enfocar la relación entre política y espacio. Espacio y espacialidad se refieren desde este punto de vista a las prácticas espaciales y a las representaciones espaciales, respectivamente, que tiene toda sociedad y que participan en la constitución de lo político:

En la mayor parte de la argumentación política contemporánea, la forma de la arena en la que las políticas (policy) son concebidas se da por supuesta. Estas arenas, que están constituidas por prácticas espaciales entre otras cosas, no son una parte audible de la argumentación política (...) Y, en general, contextualizan y de ese modo dan coherencia a los discursos que confieren significado y valor a las cosas, acciones y relaciones (Shapiro y Neaubauer, 1990:99).

De este modo los procesos políticos no pueden ser estudiados al margen del espacio, porque el espacio es constitutivo de los mismos: "Los procesos políticos son, entre otras cosas, luchas sobre las formas de entender alternativas inmanentes a las prácticas de representación que comprenden las acciones y los objetos que uno reconoce y los espacios variados - de ocio, de trabajo, políticos, privados, públicos - dentro de los que las personas y las cosas toman sus identidades" (Shapiro, 1989:12). 


\section{Heriberto Cairo}

Ésta, sería, definitivamente, una base para el desarrollo de una teoría política situada, es decir, con una amplia mirada "espacial". Además de Michael Shapiro, otros autores han venido desarrollando una teoría política con estas características. Quizás agruparlos en un sólo conjunto como "deconstruccionistas" no sea legítimo, pero la práctica de la deconstrucción es bastante común en todos ellos, si entendemos que en la deconstrucción, originalmente practicada por Derrida, el autor observa las antinomias, cuyos términos están en una oposición estructurante, y "deconstruye" esas oposiciones. Rob Walker $(1988 ; 1993)$ es uno de estos casos. Su principal crítica a la teoría política moderna se centra en que da por supuesto el hecho fundacional de la teoría y práctica política contemporánea: la concepción de que la auténtica vida política tiene lugar en el contenedor territorial del Estado soberano. El objeto de gran parte de su trabajo es el análisis crítico de las teorías políticas modernas sobre las relaciones internacionales, que considera "como un discurso que reifica sistemáticamente una ontología espacial históricamente específica, una delimitación radical del aquí y el allí, un discurso que a la vez expresa y afirma constantemente la presencia y ausencia de vida política dentro y fuera del Estado moderno" (Walker, 1993:ix).

Ashley $(1987 ; 1989)$, por su parte, reclama la utilidad de la Geopolítica, que considera con notables similitudes a la actitud genealógica, en el análisis de las relaciones internacionales: "como la Geopolítica, una actitud genealógica se ocupa del movimiento, el espacio, la estrategia y el poder" (Ashley, 1987:411). Su utilidad se deriva de que la comunidad internacional es un producto, nunca completo, de múltiples prácticas históricas, en el que continuamente están en competición estrategias y códigos que pretenden normalizar el mundo mediante la proyección de la dominación.

Connolly $(1989 ; 1991 ; 1993)$ cuestiona también la idea de que la política tenga un lugar adecuado sólo en el interior del Estado, que conlleva que la democracia sólo sea posible en el territorio soberano. Connolly (1993) intenta articular las posibles condiciones para una práctica democrática en un mundo en que la territorialidad intensifica el deseo de una identidad estable a la vez que se opone a su realización. Esto ocurriría así porque las identidades basadas en entendimientos intensamente compartidos entre los sujetos, como son las estructuradas por la territorialidad, incluyen límites rígidos. Para la extensión de la prácti- 
ca democrática se precisaría el dominio de identidades con ataduras laxas al territorio.

La espacialidad de la política no es inmutable porque "la organización espacial de la sociedad humana es un producto cambiante de la acción humana, una forma de construcción social" (Soja, 1980: 210). En este sentido y como ya hemos argumentado antes, los sistemas de gobierno o la organización política de una comunidad no tendrían por qué ser territoriales, como en los sistemas clánicos o de grupos de parentesco, o tener una delimitación territorial permanente, como en el caso de los nómadas. Entonces, considerar que las actividades políticas están territorializadas supone extender una característica particular de las comunidades políticas modernas (los Estados-nación) a toda comunidad política.

En definitiva, cuando se entiende que la actividad política está constituida espacialmente, se considera que no se puede comprender y explicar lo político sin tener en cuenta los discursos espaciales, las presunciones sobre el espacio político de una sociedad. Los hechos políticos quedan así "situados", ya no ocurren en "escenarios" más o menos neutrales o más menos determinantes, sino que la definición de los "escenarios" forma parte de los mismos hechos.

\section{EL ESPACIO ESTÁ POLÍTICAMENTE DEFINIDO Y LA POLÍTICA ESTÁ SITUADA}

Asentándonos sobre las críticas a la teoría política modernista que acabamos de revisar, e intentando ir más allá de la constatación de que el espacio es un producto social, podemos afirmar el punto de partida de nuestra propuesta: el espacio está políticamente definido y la política se encuentra situada, es decir, es inseparable del escenario en el que se desarrolla. Es en este sentido que Elden, a través del análisis del pensamiento de Heidegger, va más allá de Lefebvre y Foucault y plantea que "hay una política del espacio porque la política es espacial" (2001:151). La posibilidad de elaborar una "historia espacial" de los hechos políticos es el lógico desarrollo de este planteamiento, y Elden (2009; 2013a) se lo plantea, en quizás los más innovadores y rigurosos trabajos sobre la genealogía del territorio realizados recientemente. Como él mismo resume, el territorio "es algo conformado por, y que conforma, procesos continuos de transformación, regulación y gobernanza" (Elden, 2013b:17).

DADOS - Revista de Ciências Sociais, Rio de Janeiro, vol. 56, nº 4, 2013 


\section{Heriberto Cairo}

Pero ahora se trata de proponer algunas rutas para alcanzar lo que nos proponíamos al principio. Así que en esta segunda parte voy a intentar mostrar algunos de los mimbres que pueden ser útiles para la elaboración de una teoría política situada. En particular me voy a ocupar primero del necesario análisis de la espacialidad para tener en cuenta no sólo la territorialidad sino también la reticularidad de la política, después pasaré a tratar la construcción de la escala para superar la limitación estadocéntrica de la teoría política modernista y, finalmente, abordaré el discurso geográfico-político como articulación de los análisis parciales que se pueden realizar. Procuraré ilustrar con ejemplos latinoamericanos estas propuestas.

\section{A) Más allá de la territorialidad: un análisis de la espacialidad que incluya la reticularidad}

Los conceptos de espacialidad y de territorialidad, que evidentemente están interrelacionados, a menudo se utilizan de forma indistinta, pero no se pueden confundir. En otro lugar (Cairo, 2001) he desarrollado más detenidamente el concepto de territorialidad. En lo que ahora nos interesa es importante identificar las dos formas principales de elaborar este concepto: la de aquellos que consideran que la territorialidad humana es distinta de la territorialidad animal y la de los que consideran que son fundamentalmente el mismo fenómeno.

Para estos últimos, la territorialidad humana es una compulsión instintiva que el hombre como todo ser animado posee para defender el territorio que habita (Ardrey, 1966; Malmberg, 1980), mientras que para los primeros se trata más bien de una característica cultural especial de los seres humanos, que se acrecienta en las sociedades más complejas - especialmente las dotadas de Estado - (Soja, 1971; Sack, 1986). Evidentemente, unos intentan naturalizar la territorialidad y los otros la consideran un hecho cultural.

La territorialidad constituye uno de los principios centrales de la teoría etológica, que entiende que es una parte innata de la conducta animal: todos los animales tenderían a mantener territorios fijos y espacios individuales, estableciendo límites y excluyendo o admitiendo en los territorios así fijados a quien ellos quisieran. Se trataría entonces de una conducta puramente instintiva, y el hombre, en tanto que animal, participaría de esa conducta. Así, los etólogos (por ejemplo, Ardrey, 1966) arguyen que la posesión y la identificación con un territorio constituyen prerrequisitos para la satisfacción de necesidades básicas 
de la gente, tales como seguridad (que permite superar la ansiedad), estímulo (que vence el tedio) y, sobre todo, identidad (que anula el anonimato). Pero esta interpretación de la territorialidad humana no puede explicar las decisiones racionales ni las ambiciones propias de los humanos, que pueden dar como resultado el abandono del territorio natal - caso de las emigraciones, que no consiguen ser explicadas mediante un argumento etológico -, o, en el extremo opuesto, la adquisición por una comunidad de más territorio del que necesita para su sostenimiento - no existe equivalente animal del imperialismo humano. En definitiva, los que consideran que la territorialidad humana es una variedad de la territorialidad animal no tienen en cuenta que los territorios y la territorialidad humana son construcciones sociales y no han tenido siempre la disposición y características actuales.

Otros autores entienden que la territorialidad humana es un rasgo fundamentalmente cultural de las sociedades humanas. Según Soja (1971) la territorialidad específicamente humana tiene tres elementos: el sentido de la identidad espacial, el sentido de la exclusividad y la compartimentación de la interacción humana en el espacio. Proporciona, entonces, no sólo un sentimiento de pertenencia a una porción particular de tierra sobre el que se tienen derechos exclusivos, sino que implica un modo de comportamiento en el interior de esa entidad. En la misma línea interpretativa, Sack (1986:19) define la territorialidad como una conducta humana que intenta influir, afectar o controlar acciones mediante el establecimiento de un control sobre un área geográfica específica: el territorio. Para él, la territorialidad humana cumple cuatro funciones básicas: fortalecer el control sobre el acceso al territorio, reificar el poder a través de su vinculación directa al territorio, desplazar la atención de la relación social de dominación y actuar como contenedor espacial de hechos y actitudes. Estaría entonces en el vértice de un gran número de acciones humanas.

Pero el mismo Sack (1986) señala que existe otra forma tan importante de relación geográfica, que es la acción por contacto. Por consiguiente, la territorialidad no es la única forma humana de actuar en el espacio; metafóricamente - y a riesgo de ser simplista - cabría decir que el ser humano puede levantar muros o tender puentes, puede intentar frenar los movimientos en el espacio o favorecer las condiciones para que los flujos se amplíen, o combinaciones de ambas conductas, como se observa si, por ejemplo, contrastamos las facilidades que las autoridades estatales han llegado a dar para el desarrollo de los flujos de capitales 


\section{Heriberto Cairo}

con las barreras que se levantan en las fronteras para impedir los flujos de personas. Entonces, se puede concluir que cualquier acción humana está asociada a una determinada espacialidad (y temporalidad), que puede afirmar la territorialidad o la conectividad, y, por tanto, que puede favorecer la construcción de comunidades políticas territoriales o comunidades políticas en red.

En el ámbito de la sociología se ha señalado suficientemente la importancia de las redes (Latour, 1991) para entender las relaciones sociales y de la sociedad con la naturaleza, o de los flujos (Deleuze y Guatari, 1980) en la constitución de los hechos sociales; incluso se han dibujado los contornos de una "sociedad en red" (Castells, 1996). Pero es menos frecuente la elaboración politológica del concepto, aunque trabajos pioneros como los de Heclo (1978) sobre las redes especializadas de políticas públicas, o más recientes como el de Schneider et al. (2003), tratan de mostrar que las redes son el núcleo de las estructuras institucionales de gobierno. En América Latina se pueden citar también los estudios sobre los mecanismos relacionales en la política (Marques, 2007) o, más en particular, sobre la importancia del estudio de las redes sociales e individuales para el diseño de políticas sociales (Marques, 2009).

Un caso interesante de reticularidad sustituyendo a la territorialidad deriva de los cambios tecnológicos que socavan el monopolio del espacio hertziano en los Estados, a través de los modernos medios de comunicación públicos, y no sólo les conduce a competir con medios privados, sino que "explicita la metáfora espacial que está profundamente enraizada en el modelo del sector público, según la cual los ciudadanos, que actúan dentro de una esfera pública integrada, auténticamente pertenecen a un territorio cuidadosamente definido que guarda el Estado-nación soberano" (Keane, 2000:75). La analogía con los medios de comunicación impresos que estudiaba Benedict Anderson analizando el surgimiento de las naciones como comunidades imaginadas es evidente, y Keane concluye que

está llegando a su fin la vieja dominación de una vida pública estructurada por el Estado y territorialmente limitada a través de diferentes medios como radio, televisión, periódicos y libros. Su hegemonía está siendo rápidamente erosionada mediante el desarrollo de una multiplicidad de espacios de comunicación en red que no están directamente vinculados a un territorio, y que por lo tanto flanquean y fragmentan lo 
que anteriormente parecía una esfera pública única, espacialmente integrada, en el marco de un Estado-nación (2000:76).

En América Latina, son dignos de mención varios trabajos sobre redes transnacionales y actores políticos globales. Por ejemplo, se han descrito las redes zapatistas transnacionales, como una construcción que va más allá de los vínculos cibernéticos construyéndose sobre la "vida organizacional de los participantes de los movimientos, redes y colectivos (Leyva Solano, 2009:126). En este sentido, Cairo y Bringel han intentado mostrar cómo se concreta esta reticulización de la política: "los activistas diaspóricos se desarrollan, al igual que los cosmopolitas enraizados, en redes transnacionales, construidas a través de múltiples referencias e identidades flexibles, aunque, a diferencia de los segundos, no tienen raíces, sino rutas (2010: 48). Los trabajos de Mato (e. g., 2004) también muestran cómo se conforma una política en red de la sociedad civil regional y global - aunque el autor insista en que los actores globales y regionales transnacionales están territorializados - a través de los "complejos de redes de actores" (2004:87).

De este modo, los perfiles de las comunidades políticas que están surgiendo no están, ni mucho menos, claros todavía, pero se apuntan una serie de rasgos característicos: las unidades políticas, de diferente tamaño, se solapan e interconectan a diversos niveles y por diferentes vías; predomina la tendencia a intercambiar flujos entre las unidades componentes frente a los deseos de establecer límites nítidos entre ellas, y, definitivamente, se multiplican los nodos de conexión y se debilitan los nodos centrales de cada unidad. Esto evidentemente apunta a que el espacio político "territorializado" de la modernidad se podría ir transformando en un espacio político "reticular", un espacio en el que los haces de líneas sustituyeran a los espacios planos, o, más ajustado a la realidad, en la actualidad el espacio político reticular se superpone, coexiste, con el territorial. Bringel, por ejemplo, propone una imbricación entre ambas miradas para pensar la dimensión territorial y reticular de los movimientos sociales como algo mutuamente constitutivo; en sus propias palabras: "una visión relacional del lugar [es] central para analizar, de forma espacializada, las relaciones entre los diferentes territorios, mediadas por redes, escalas y dinámicas de difusión, típicas del activismo contemporáneo" (Bringel, 2012:54-55). Si desarrollamos esa perspectiva podremos ver cómo los movimientos sociales se insertan en diferentes lugares, redes y temporalidades (Bringel, 2011), en el sentido planteado también por Nicholls (2009). 


\section{Heriberto Cairo}

La diferencia fundamental entre un espacio "territorializado" y uno "reticular" es que "la lógica territorial se basa en la proximidad topográfica y conduce a una homogeneidad espacial, mientras que las redes están relacionadas con la proximidad topológica y generan espacios heterogéneos" (Prevelakis, 2000: 5). Y estos últimos no son enteramente novedosos; por ejemplo, el Mediterráneo prewestfaliano que describe Braudel (1966) en su obra magistral respondería a este modelo. Una teoría política situada se ocupará entonces de analizar no sólo los hechos políticos territoriales sino también los reticulares, de modo que se incorporen en el análisis todas sus dimensiones.

\section{B) La producción de la escala: "pensar geopolíticamente la democracia"}

En un magnífico libro reciente Luis Tapia (2009) desarrolla la idea de que la noción de "espacio-tiempo" aplicada a una formación social permitiría mostrar como la política es "una articulación de territorio, población y forma de gobierno y dirección [...] [e] implica un modo de relacionamiento con la naturaleza" (Tapia, 2009: 33). Ésta es una propuesta interesante que enlaza explícitamente con los trabajos de sociología histórica de Theda Skocpol, Michael Mann o Charles Tilly, que efectivamente consigue mostrar que la política, en tanto que articulación macro, ha de ser analizada en formaciones histórico-geográficas específicas. Pero, desde mi punto de vista, la parte más innovadora del libro es la que plantea que hay que "pensar geopolíticamente la democracia". Se trata, según el autor, de traer a la luz las asimetrías y desigualdades intergubernamentales e interestatales que se producen derivadas del imperialismo. Si la geopolítica es una estrategia espacial de ordenación de la sociedad y de sus vínculos con la naturaleza, la geopolítica desarrollada desde los (euro)centros del sistema mundial implica la extensión de un modelo procedimental de la democracia, que la reduce a la selección de los gobernantes cada cierto tiempo. La homogeneización universal de este procedimiento reduce el autogobierno de las sociedades colonizadas, y la introducción de la "propiedad privada cancela las prácticas de reciprocidad o complementariedad que suelen acompañar a las formas comunitarias de cultura agraria" (Tapia, 2009: 110), y sólo pensando la forma en la que esto se ha producido, es decir, pensando geopolíticamente la democracia, se pueden comprender las raíces y mecanismos de este proceso político: el imperialismo. 
En lo esencial, Tapia está produciendo una "política de escala", en el sentido de Neil Smith (1992). Analizar un hecho político a diferentes escalas permite ver los diferentes procesos que intervienen en él. Se trata de un análisis "diatópico" - expresión acertadamente acuñada por Foucher (1986) por analogía a la noción de diacronía - que estudia los problemas que conforman una situación mediante el análisis de los conjuntos espaciales originados por los diferentes fenómenos que contribuyen a definirla, conjuntos que se han de identificar de acuerdo con diferentes escalas espaciales.

El carácter esencialmente geográfico de este tipo de análisis nos aparece claro si tenemos en cuenta que, como señala Bunge (1983), los geógrafos ensamblan la información mediante la cartografía, información que es transformada a través de su proyección en mapas. En estos mapas, dependiendo de la escala a la que estén realizados, se pueden reunir o no determinadas informaciones; por ejemplo, para un geógrafo es evidente que los desplazamientos o los lugares de la vida cotidiana de los seres humanos hay que inscribirlos en mapas a gran escala, mientras que para estudiar los conjuntos espaciales que configuran las diversas civilizaciones ha de recurrirse a mapas a muy pequeñas escalas.

Lacoste, un geógrafo clave en la "resurrección" radical de la geopolítica, propone realizar el "análisis de los fenómenos de espacialidad diferencial", que se basa "en la investigación sistemática de los diferentes conjuntos espaciales a que pertenecen el punto o el espacio en cuestión. Cada uno de estos diferentes conjuntos espaciales sólo explica parcialmente unas características globales que hay que tener en cuenta para actuar en este lugar o en este espacio" (1976 [1977: 144]). Es importante considerar que estos conjuntos espaciales no tienen ni mucho menos la misma extensión. Las dimensiones de los conjuntos que se analizan en los distintos niveles del sistema global son muy diferentes, y en cada uno de estos "estratos", se da "una disposición peculiar de variables específicas, y entonces se pueden estudiar de manera individual" (Foucher, 1986: 44). Cada escala, cada nivel espacial, corresponde, por tanto, a un nivel diferente de conceptualización. Pero si los diferentes niveles de análisis espacial de hecho se corresponden con diferentes niveles de conceptualización, ya no se trata sólo de diferenciar e individualizar, sino que en tanto que estos estratos son interdependientes, se ha de operar de un modo en el que se pongan de manifiesto las interrelaciones. 


\section{Heriberto Cairo}

El análisis de sistemas-mundo argumenta que el análisis se debe desarrollar en tres escalas básicas: la economía-mundo, el Estado-nación y la localidad, que constituyen, desde este punto de vista, la "división vertical" del sistema-mundo (Taylor, 1984; 1987). La utilización de esos tres niveles de análisis no es original del análisis de sistemasmundo, sino que constituye algo habitual en la geografía política más reciente, pero en la mayor parte de los enfoques es meramente un instrumento analítico mientras que en el análisis de sistemas-mundo es un hecho político fundamental en la investigación:

La principal ventaja de este enfoque es que se asegura de que, en vez de aceptar la escala meramente como un principio de organización, nos encaminemos a preguntarnos por qué lo político ocurre a una escala particular. No hay nada neutral acerca de la escala geográfica en la que cualquier conflicto se decide. Por cada escala "escogida" hay otras olvidadas, que podrían haber ofrecido resultados alternativos. Así, lo que sacamos a la palestra son las relaciones entre las escalas y su diferente significado político. (...) La escala geográfica es política (Taylor, 1984:6).

Conviene tener en cuenta, antes de seguir adelante, que el problema de la escala, tal y como lo plantea Taylor, no se encuentra en absoluto alejado de las posiciones que hemos visto en Lacoste y Foucher; se trata en todos los casos de analizar los problemas a diversas escalas y de articular esos diferentes niveles de análisis. La perspectiva geográfico-política del análisis del sistema mundial implicaría una particular selección de escalas de análisis y la formulación de forma específica de las relaciones entre ellas. Entiendo que esta perspectiva puede ser muy útil metodológicamente en la medida que se corrijan los riesgos reduccionistas ya señalados anteriormente, de tal forma que se precisen bien el origen, desarrollo y alcance de los procesos de homogeneización a escala planetaria y de diferenciación en el ámbito local, y sin intentar hacer depender, aunque sea en última instancia, todas las escalas de la de la economía-mundo.

Por último, conviene tener en cuenta que cuando se ejecuta un tipo de análisis como el que proponemos, cabe siempre el peligro de entender la descripción de un espacio considerado a determinada escala como el espacio real, siendo los otros dependientes de éste. También puede ocurrir que se considere el análisis a determinada escala como el fundamental, en tanto que los procesos objeto de análisis a esa escala se consideren determinantes del fenómeno, y en esa medida se descuiden 
otras escalas. Estamos expuestos, en suma, a la amenaza de practicar un análisis reduccionista.

El origen del problema suele estar en el carácter diverso que tiene para diferentes actores la misma porción de espacio; por ejemplo, lo que para unos es un lugar de recolección de frutos y de caza para garantizar su sustento, para otros es un "contenedor" de maderas preciosas que se pueden convertir en mercancías mediante las cuales obtener beneficio económico o, excluyendo muchas otras posibilidades, para otros es una área productora de oxígeno de vital importancia para la supervivencia de toda la humanidad. Y no podemos reducir la realidad del bosque tropical del ejemplo a uno sólo de los procesos en marcha en ese lugar. Como señala Lefebvre, "el espacio concreto no coincide con ninguna de las divisiones que el analista efectúa en él; se concibe como un envolvimiento de niveles sucesivos" (1974: 248), que para algunos podría recordar a las capas de una cebolla, aunque no estimamos demasiado afortunada la comparación, ya que el cambio de escala implica un cambio cualitativo. En todo caso, conviene tener presente que el análisis diatópico no identifica varias realidades, sino que deconstruye la realidad.

Finalmente - y volviendo de nuevo a Tapia -, pensar geopolíticamente la democracia "implica acompañarla de estrategias de desmontaje del imperialismo y, también, del capitalismo en lo internacional y en lo nacional [...] La dimensión geopolítica de la democracia implica pensar y organizar un nivel de intergubernamentalidad en condiciones de igualdad entre diferentes formas y unidades de autogobierno" (Tapia, 2009:91). Es decir, nos encontramos ante un tipo de razonamiento estratégico, o, en palabras de Lacoste, una forma de "saber pensar el espacio para saber organizarse en él, para saber combatir en él" (1976 [1977:135]). Sin esta clave no se puede entender completamente la propuesta del método de análisis diatópico: la colaboración eficaz en la comprensión de los problemas sociales, políticos y económicos ha de ser uno de los objetivos de este análisis, pero esa eficacia ha de orientarse a la intervención, más allá de la reconstrucción de razonamientos.

\section{C) Los discursos geográfico-políticos: articulando prácticas, estructuras y narrativas}

Compartimos la idea sobre la necesidad de superar los enfoques que reducen la explicación en Ciencias Sociales - aunque sólo sea "en últi- 


\section{Heriberto Cairo}

ma instancia" - a factores económicos o políticos, pero es importante no caer en tentaciones neoplatónicas. Efectivamente, aunque el discurso constituya relaciones de poder y se vaya conformando en las mismas, antes y después del discurso existen prácticas sociales relevantes en la organización de estructuras espaciales, sin cuya comprensión no podemos entenderlas. Como señala con precisión Lefebvre, "el espacio ha sido producido antes de ser leído, y no ha sido producido para ser leído y conocido, sino para ser vivido por gente que tiene un cuerpo y una vida [...]. En otras palabras, la lectura viene después de la producción" (1974:168; el énfasis es mío). Es decir, que las estructuras espaciales se producen históricamente con el objetivo de dar un cauce determinado a las personas, de conducir sus cuerpos y sus vidas. En este sentido, es irrelevante si este encauzamiento responde a una necesidad objetiva en el terreno de lo político o de lo económico; lo importante es entender que la estructura espacial es una estructura de dominación, en el sentido de Giddens ${ }^{5}$, tanto política como económica.

En el proceso de producción de estas estructuras, es necesario establecer su legitimación - a través fundamentalmente de un sistema de sanciones, que maneja normas de carácter moral - y adquieren una significación precisa en el sistema de comunicación; pero no son producidas pensando en el sistema comunicativo, aunque el elemento simbólico constituya parte integrante fundamental sin el que no se podría explicar el sistema completo. Y a fin de comprender el espacio como "producto social" hay que superar las dos "disimulaciones" que señalaba Lefebvre (1974): la "ilusión de la transparencia" y "la ilusión realista", es decir, la creencia en la explicación simbólica o en la materialista, exclusiva y excluyentemente.

La "trialéctica" que establece Lefebvre entre "prácticas espaciales", "representaciones del espacio" y "espacios de representación" es un instrumento útil para evitar ambas ilusiones. Las prácticas espaciales se refieren a actividades en lugares y conjuntos de lugares interrelacionados que se organizan en las formaciones sociales para la producción económica y la reproducción social. Las representaciones del espacio implican signos, códigos y formas de entender que hacen inteligibles a los seres humanos las prácticas espaciales. Y los espacios de representación son las geografías imaginadas de los grupos subalternos, que son la clave en las transformaciones del sistema de representación y que "presentan simbolismos complejos, ligados a la parte clandestina y oculta de la vida social" (Lefebvre, 1974:43). Es bastante claro que los 
tres conceptos están estrictamente interrelacionados y ninguno está situado en una posición preeminente, a fin de evitar las "ilusiones" a las que se refería Lefebvre. La conexión de los diferentes planos que se pueden distinguir en el análisis se realiza en la práctica humana histórica concreta; es decir, que la realidad es compleja y no es reducible a uno de sus componentes.

La noción de discurso de Michel Foucault (1963; 1976), tal y como es desarrollada en dos de sus trabajos sobre la genealogía de discursos específicos, como son el clínico y el sexual, también incluiría tanto el lenguaje como su materialidad en las instituciones y las prácticas sociales. El poder de los discursos, de hecho, derivaría de su institucionalización y de su práctica. Para Foucault un discurso es un conjunto de enunciados y depende de la misma formación discursiva; que a su vez necesita para ser mínimamente efectivo un conjunto de "condiciones de existencia" o "condiciones de posibilidad", a cuya creación a la vez contribuyen. De esta forma, el discurso geopolítico se podría situar al lado de otros que Foucault trabajó, como el discurso clínico, el discurso de la historia de las ideas en Occidente y el discurso psiquiátrico.

Foucault también nos puede arrojar algo más de luz sobre las relaciones entre prácticas y representaciones del espacio, gracias a la distinción que establece entre "formaciones prácticas" "discursivas" y "no-discursivas":

Las formaciones discursivas [...] [existen en relación a] masas y poblaciones que dependen de otro tipo de formación, e implican medios no discursivos (instituciones, acontecimientos políticos, prácticas y procesos económicos). Ciertamente, los medios producen también enunciados, y los enunciados determinan los medios. Sólo que las dos formaciones son heterogéneas, aunque estén insertadas la una en la otra: no hay correspondencia ni isomorfismo, no hay causalidad ni simbolización (Deleuze, 1986:39).

Las representaciones del espacio (en términos de Lefebvre) son formaciones discursivas (en términos de Foucault) que están insertadas en formaciones no-discursivas y viceversa. Las interpretaciones, lecturas, materialistas de la "realidad", especialmente el marxismo tradicional, parte de las formaciones no-discursivas para entender las formaciones discursivas, pero se ha demostrado la fertilidad teórica de leer ambas formaciones también en un sentido inverso; por ejemplo, el concepto de "espectáculo", que Debord - siempre en debate con 


\section{Heriberto Cairo}

Lefebvre - elabora, y respecto al cual señala: "el espectáculo no es un conjunto de imágenes, sino una relación social entre personas, mediatizada a través de imágenes" (1969 [1974:70]), que tiene que ser leída a través de ellas.

Representaciones geopolíticas del espacio, como las que están inscritas en la nuevas teorías del intervencionismo humanitario, no son el resultado de presiones económicas o políticas para dominar espacios como Sierra Leona, Liberia o Somalia, que son directamente descritos como "agujeros negros", sino que son más bien instrumentales para hacer un nuevo uso de viejas instituciones, como los poderosos ejércitos que se habían construido durante la Guerra Fría, o para regular la economía de las industrias armamentísticas.

En definitiva, los discursos geográfico-políticos son inseparables de y están constituidos por las representaciones geopolíticas y las prácticas geopolíticas. De estas últimas derivan su poder, a la par que condicionan su inteligibilidad. Son, en otras palabras, retórica y praxis. En lo referente a la parte retórica de los discursos, está conformada por diversos "enunciados", en palabras de Foucault, o "narrativas" según otros autores. En las narrativas "los hechos se estructuran de tal manera que se convierten en componentes de una historia particular" (Campbell, 1998:34), que crea un orden de significados en los hechos narrados. Es conveniente distinguir entre las "micronarrativas" de los actores políticos y las "macronarrativas" de los medios de comunicación y de los académicos, que obviamente están relacionadas pero desempeñan papeles diferentes ${ }^{6}$ (Campbell, 1998:43).

Por último, hay un problema que debemos considerar en estos momentos. ¿Cómo y sobre qué base se genera este espacio producto social? En otras palabras, debemos considerar la existencia o no de un espacio absoluto, previo a las estructuras espaciales que son producto de las acciones humanas, e irreducible a las mismas, como ocurría en el caso de los que consideran el espacio un escenario de la acción política. Al entender el espacio como algo que se produce, el proceso de producción ha de partir de alguna "materia prima", que no puede ser otra que "la naturaleza" (Lefebvre, 1974), y podría parecer entonces que efectivamente cabría la posibilidad de distinguir entre un espacio "natural", preexistente, y un espacio "social", resultante - eso sí - de un proceso de producción mucho más complejo que el de cualquier otra mercancía 
en el que interviene no sólo lo económico, la técnica, sino también lo político, la estrategia.

Este espacio social, que es más que una relación social o una superestructura, se manifiesta polivalente: "Este medio de producción, producto en cuanto tal, no se puede separar ni de las fuerzas productivas, de las técnicas y del saber, ni de la división del trabajo social, que le da forma, ni de la naturaleza, ni del Estado y las superestructuras" (Lefebvre, 1974:102). En otras palabras, no tiene ningún sentido pensar en procesos puramente espaciales, que puedan preceder, influir, o incluso determinar, los procesos políticos que se desarrollarían sobre ellos; no tiene ningún sentido esta forma de separar lo político de lo espacial.

Sin embargo, por otro lado, "la geografía también importa" (Massey, 1984), las estructuras espaciales no son únicamente el resultado de procesos sociales particulares: ésta sería otra forma de separar lo político y lo espacial. Los procesos políticos no se producen en un mundo indiferenciado físicamente, sin variaciones climáticas, de vegetación, de relieve, etc.; peculiaridades cuyo uso, impacto o significado será determinado, a su vez, por procesos políticos, económicos, culturales, etc.; es decir, que no se pueden entender los unos sin los otros, pero ninguno predetermina o resulta de otro, por cuanto son simplemente partes inseparables constitutivas de la realidad, aunque en ocasiones el analista científico las diseccione.

\section{CONCLUSIONES}

Las ciencias sociales, por más que algunos lo pretendan, no constituyen compartimentos estancos, sino que, tal y como afirma Foucault, "se entrecruzan y pueden siempre interpenetrarse las unas a las otras, sus fronteras se desvanecen, [y] las disciplinas intermedias y mixtas se multiplican indefinidamente" (cit. en Reynaud, 1982:11). Entonces, "existen áreas donde el trabajo interdisciplinario busca establecer nexos entre los intereses y las perspicacias de disciplinas diferentes" (Held y Leftwich, 1984 [1987:272]). En el caso de la Ciencia Política existen varias de estas disciplinas intermedias o campos híbridos, entre otras la Sociología Política, la Economía Política, la Psicología Política, la Filosofía Política y en lo que a este trabajo concierne, la Geografía Política. 
El afán de definir con precisión las disciplinas que se generaron en los siglos XVIII y XIX es consecuencia, en última instancia, de la lucha por lograr extender la influencia personal o grupal en el ámbito académico y, por lo tanto, el dominio que conduce a una situación privilegiada, ya sea desde un punto de vista económico o desde cualquier otro. Numerosas disputas "científicas" no son más que luchas por privilegios; en este sentido, por ejemplo, la agria disputa que a principios de siglo enfrentó a Durkheim y a Vidal de la Blache, así como a varios de sus discípulos, aunque fue mantenida en términos científicos no puede entenderse al margen de los intereses institucionales de unos y otros, de las entonces nacientes Sociología y Geografía.

Desde la perspectiva del conocimiento, este tipo de actitud es completamente estéril, pues no sólo no conduce a una mayor precisión explicativa, sino que a la postre en numerosas ocasiones los rivales desvirtúan por completo los argumentos científicos en aras de una mayor contundencia. Con ironía denuncia Piatier este tipo de conductas: "El mandarín que en la Universidad pasa más tiempo defendiendo la frontera de su disciplina que desbrozándola no es muy diferente del mono que marca los límites de su zona reservada con sus excrementos" (cit. en Miossec, 1976: 166).

En lo tocante a nuestra propuesta de una teoría política situada, habría que comenzar señalando que en la medida que las prácticas espaciales se estructuran, se convierten en pautas perdurables que contienen la acción política en cada comunidad, mientras no entren en crisis y, por tanto, no sean aceptadas, o no puedan ser impuestas. Pero la posibilidad de crisis de las pautas de ejercicio de las prácticas espaciales siempre está abierta porque la concepción del espacio es cambiante ${ }^{7}$ en los grupos sociales. La concepción del espacio - o el tiempo - como algo absoluto ha ido perdiendo vigencia, cuando menos desde la exposición de las teorías físicas einsteinianas, pero quizás haya sido en Ciencias Sociales donde menos consecuencias se hayan extraído de esta nueva concepción, porque hay que entender que "cada formación social construye concepciones objetivas del espacio y del tiempo suficientes para sus propias necesidades y propósitos de reproducción material y social, y organiza sus prácticas materiales de acuerdo con estas concepciones" (Harvey, 1990:419).

Y es importante subrayar que no se está hablando de percepciones subjetivas cambiantes de una realidad que pudiese estar por encima de las 
relaciones sociales, sino de la construcción de "concepciones objetivas", de estructuras espaciales - y temporales - específicas de cada formación social. En este sentido, a nuestro entender, las posiciones teóricas que ven en el discurso político - o geográfico-político - un mero instrumento justificador de una determinada práctica olvidan que el discurso ideológico goza de una autonomía que genera unas relaciones de poder propias que en numerosas ocasiones conducen, por encima de otras consideraciones, a la toma de ciertas decisiones.

Dos son las consecuencias más relevantes para nuestra exposición: no pueden examinarse los fenómenos espaciales al margen de los sociales o políticos y, a la vez, los hechos políticos no pueden entenderse al margen de los constructos espaciales de cada sociedad. Por lo tanto, habría que evitar con ahínco una teoría política que intente operar en el seno de una ciencia del espacio inútil, que, como señala Henri Lefebvre, "se dispersa y se pierde en consideraciones variadas sobre lo que hay en el espacio, o sobre el espacio abstracto" (1974:164) - y esto es así, porque no existe un espacio separado e independiente de cada sociedad concreta-, pero los hechos políticos no pueden ser explicados sin tener en cuenta los contextos, discursos y prácticas espaciales en los que se producen y que producen.

(Recebido para publicação em maio de 2013)

(Reapresentado em setembro de 2013)

(Aprovado para publicação em novembro de 2013) 


\section{Heriberto Cairo}

\section{NOTAS}

1. Para un tratamiento más amplio de esta cuestión véase Shapiro (2001:89-105).

2. Uno debe ser precavido y no confundir la eficiencia de la institución con ideas como la de que "el Estado existe porque la gente lo necesita y lo quiere" (Buckholts, 1966:488). Describir el Estado como una institución "natural" que emana de la voluntad de las gentes es cometer el despropósito de pensar que la única existencia posible es la que conocemos actualmente.

3. "Los ashanti, yoruba, hausa, mosi, wolof o aal pulaar, que han desarrollado una avanzada tesitura estatal, revelan densos aparatos conceptuales. A menudo discrepan en lo esencial de los registros que exploran a este nivel. Sobreponen a los 'amos del espacio' los 'amos del poder', que aparecen con la autoridad política propiamente dicha y del Estado como país y conjunto institucional [...] En el África negra el dominio del espacio es anterior con respecto al del poder. La preeminencia del 'jefe político' sobre el 'jefe territorial' es el fruto de una evolución, a veces tardía, que ha diferenciado progresivamente entre las instancias, las del lamanat, o dominio del espacio territorial, de las del mansaya, o dominio del espacio político" (Diagne, 1981 [1983:29]).

4. El cuestionamiento de las concepciones tradicionales del espacio ya se había producido en otras disciplinas con anterioridad. El ejemplo quizás más claro es el de la Física relativista.

5. Giddens propone incluir el concepto marxista de "explotación" dentro de otro que considera más genérico, el de "dominación", que entiende como "el dominio que los actores tienen sobre otros y sobre el mundo material que habitan" (1981:50). La estructura de "dominación" incluiría tanto el ámbito político como económico, que, para él, si bien se pueden distinguir analíticamente, no son separables estructuralmente.

6. Hay que tener en cuenta la necesaria contextualización de ambas, dado que se relacionan y configuran de formas variables, como muestra, por ejemplo, Lois (2008) en su trabajo sobre un pequeño municipio gallego con fuerte implantación nacionalista.

7. Los grandes rasgos del cambio sólo se pueden percibir en la longue durée. Los análisis coyunturales para aprehender los cambios de concepción social del espacio pueden llevar en ocasiones a falsas concepciones. 


\section{BIBLIOGRAFÍA}

AGNEW, John y CORBRIDGE, Stuart. (1995), Mastering Space: Hegemony, Territory and International Political Economy. London, Routledge.

ARDREY, Robert. (1966), The Territorial Imperative. New York, Atheneum.

ASHLEY, Richard K. (1987), "The Geopolitics of Geopolitical Space". Alternatives, vol. 12, pp. 403-434.

. (1989), “Living on Border Lines: Man, Poststructuralism, and War", en J. Der Derian y M. J. Shapiro (eds.), International/Intertextual Relations: Postmodern Readings of World Politics. New York, Lexington Books, pp. 259-321.

BRAUDEL, Fernand. (1966), La Méditerranée et le Monde Méditerranéen a l'Époque de Philippe II (2a ed.). Paris, Armand Colin [trad. al castellano de M. Monforte Toledo, W. Roces y V. Simón (1976), El Mediterráneo y el Mundo Mediterráneo en la Época de Felipe II. México, Fondo de Cultura Económica].

BRINGEL, Breno. (2011), “Ativismo Transnacional, o Estudo dos Movimentos Sociais e as Novas Geografias Pós-coloniais". Estudos de Sociologia, vol. 16, oㅡ 2, pp. 185-215.

. (2012), “Com, Contra e para Além de Charles Tilly: Mudanças Teóricas no Estudo das Ações Coletivas e dos Movimentos Sociais". Sociologia \& Antropologia, vol. 2, no3, pp. 43-67.

BUCKHOLTS, Paul. (1966), Political Geography. New York, Ronald Press.

BUNGE, William W. (1983), “Geography is a Field Subject". Area, vol. 15, pp. 208-210.

CAIRO, Heriberto. (2001), “Territorialidad y Fronteras del Estado-nación: Las Condiciones de la Política en un Mundo Fragmentado". Política y Sociedad, vol. 36, pp. 29-38.

y BRINGEL, Breno M. (2010), “Articulaciones del Sur Global: Afinidad Cultural, Internacionalismo Solidario e Iberoamérica en la Globalización Contrahegemónica". Geopolítica(s). Revista de Estudios sobre Espacio y Poder, vol. 1, no 1, pp. 41-63.

CAMPBELL, David. (1998), National Deconstruction: Violence, Identity, and Justice in Bosnia. Minneapolis, University of Minnesota Press.

CASTELLS, Manuel. (1996), The Rise of the Network Society. The Information Age: Economy, Society and Culture Vol. I. Cambridge, Ma., y Oxford (RU), Blackwell.

CONNOLLY, William E. (1989), “Identity and Difference in Global Politics”, en J. Der Derian y M. J. Shapiro (eds.), International/Intertextual Relations: Postmodern Readings of World Politics. New York, Lexington Books, pp. 323-342.

(1991), Identity/Difference: Democratic Negotiations of Political Paradox. Ithaca, Cornell University Press.

. (1993), “Democracy and Territoriality”, en F. M. Dolan y T. L. Dumm (eds.), Rethorical Republic: Governing Representations in American Politics. Amshert, University of Massachusetts Press, pp. 249-274.

DAHL, Robert A. (1970), Modern Political Analysis (2a ed.). Englewood Cliffs (N.J.), Prentice-Hall [trad. al castellano por R. Ribó (1976), Análisis Político Moderno. Barcelona, Fontanella]. 


\section{Heriberto Cairo}

DEBORD, Guy. (1969), La Societé du Spectacle. Paris, Buchet-Chastel [trad. al castellano por J. Diamant (1974) La sociedad del espectáculo. Buenos Aires, Ediciones de la Flor].

DELEUZE, Gilles. (1986), Foucault. Paris, Les Éditions de Minuit.

y GUATARI, Felix. (1980), Mille Plateaux. Paris, Les Éditions de Minuit.

DIAGNE, Pathé. (1981), “Le Pouvoir en Afrique”, en I. A. Akinjogbin, P. Diagne, G. Hagan, O. Konaré, B. Kossou, S. Nsabimana y B. Tafla. Le Concept de Pouvoir en Afrique. Paris, Unesco [trad. al castellano por F. Iniesta, "El poder en África”, en I. A. Akinjogbin et al. (1983), El Concepto del Poder en África. Barcelona, Serbal/UNESCO, pp. 27-52].

ELDEN, Stuart. (2001), Mapping the Present: Heidegger, Foucault and the Project of a Spatial History. London, Continuum.

(2009), Terror and Territory: The Spatial Extent of Sovereignty. Minneapolis, University of Minnesota Press.

(2013a), The Birth of Territory. Chicago, University of Chicago Press.

(2013b), "How should we do the History of Territory?". Territory, Politics, Governance, vol. 1, no 1, pp. 5-20.

FOUCAULT, Michel. (1963), Naissance de la Clinique: Une Archéologie du Regard Médical. Paris, PUF [trad. al castellano por F. Perujo (1966), El Nacimiento de la Clínica: Una Arqueología de la Mirada Médica. México, Siglo XXI].

. (1975), Surveiller et Punir. Naissance de la Prison. Paris, Gallimard [trad. al castellano (1976), Vigilar y Castigar. México, Siglo Veintiuno].

(1976), “Questions à Michel Foucault sur la Géographie". Hérodote, 1, pp.71-85 [trad. al castellano "Preguntas a Michel Foucault sobre la Geografía”, en Michel Foucault (1978), Microfísica del Poder (eds. y trads. J. Varela y F. Alvárez-Uría). Madrid, La Piqueta, pp. 111-124].

FOUCHER, Michel. (1986), L'Invention des Frontières. Paris, Fondation pour les Études de Défense Nationale.

GIDDENS, Anthony. (1981), A Contemporary Critique of Historical Materialism. London, Macmillan.

. (1987), The Nation-State and Violence. Volume two of A Contemporary Critique of Historical Materialism. Berkeley, University of California Press.

HARVEY, David. (1990), "Between Space and Time: Reflections on the Geographical Imagination". Annals of the Association of American Geographers, vol. 80, no 3, pp. 418-434.

HAUSHOFER, Karl. (1927), "Greographische Grundzüge auswärtige Politik”. Süddeutsche Monatshefte, no 9, pp. 258-261. [Trad. al castellano por M. Díaz (2012) “Los fundamentos geográficos de la política exterior". Geopolítica(s). Revista de Estudios sobre Espacio y Poder, vol. 3, no 2, pp. 329-336].

HECLO, Hugh. (1978), "Issue Networks and the Executive Establishment", en A. King (ed.), The New American Political System. Washington, DC, American Enterprise Institute, pp. 87-124. 
HELD, David y LEFTWICH, Adrian. (1984), "A Discipline of Politics?”, en A. Leftwich (ed.), What is Politics? The Activity and its Study. Oxford, Basil Blackwell [trad. al castellano por E. Niño de la Selva (1987), “¿Una disciplina de la Política?”, en ¿Qué es la Politica? La Actividad y su Estudio. México, Fondo de Cultura Económica, pp. 254-290].

KEANE, John. (2000), "Structural Transformations of the Public Sphere”, en K. L. Hacker y J. van Dick (eds.), Digital Democracy: Issues of Theory \& Practice. London, Sage, pp. 70-89.

LACOSTE, Yves. (1976), La Géographie, ça Sert, d'Abord, à Faire la Guerre. Paris, F. Maspero [trad. al castellano por J. Jordá (1977), La Geografía: Un Arma para la Guerra. Barcelona, Anagrama].

LATOUR, Bruno. (1991), Nous n'avons jamais été Modernes. Essai d'Anthropologie Symétrique. Paris, La Découverte.

LEFEBVRE, Henri. (1974), La Production de l'Espace. Paris, Anthropos.

LÉVY, Jacques. (1994), L'Espace Légitime. Sur la Dimension Géographique de la Fonction Politique. Paris, Presses de la Fondation Nationale des Sciences Politiques.

LEYVA SOLANO, Xochitl. (2009), “Nuevos Procesos Sociales y Políticos en América Latina: Las Redes Neozapatistas", en R. Hoetmer (coord.), Repensar la Política desde América Latina: Cultura, Estado y Movimientos Sociales. Lima, Universidad Nacional Mayor de San Andrés/Programa Democracia y Transformación Global, pp. 109-130.

LOIS, María. (2008), "Place and Marketplace: Reconstructing Sites in the World-Economy". Review (Fernand Braudel Center), vol. 31, no 4, pp. 493-509.

MALMBERG, Torsten. (1980), Human Territoriality. La Haya, Mouton.

MANN, Michael. (1984), "Capitalism and Militarism”, en M. Shaw (ed.), War, State and Society. London, Macmillan, pp. 25-46.

(1993), The Sources of Social Power. Volume II: The Rise of Classes and Nation-States, 1760-1914. Cambridge, Cambridge University Press.

MARQUES, Eduardo. (2007), “Os Mecanismos Relacionais". Revista Brasileira de Ciências Sociais, vol. 22, no 64, pp. 157-161.

(2009), Redes Sociais, Segregação e Pobreza em São Paulo. São Paulo, Edusp.

MASSEY, Doreen. (1984), Spatial Division of Labour: Social Structures and the Geography of Production. London, Macmillan.

MATO, Daniel. (2004), "Redes Transnacionales de Actores Globales y Locales en la Producción de Representaciones de Ideas de Sociedad Civil", en D. Mato (coord.), Politicas de Ciudadanía y Sociedad Civil en Tiempos de Globalización. Caracas, FACES/Universidad Central de Venezuela, pp. 67-93.

MIOSSEC, Jean-Marie. (1976), “Espace et Pouvoir. La Localisation des Forces de Décision dans le Monde: Esquisse de Géographie Politique Théorique". L'Espace Géographique, vol. 5, no 3, pp.165-175.

MONTESQUIEU (1748), L'Esprit des Lois [trad. al castellano (1964), El Espíritu de las Leyes. Río Piedras, Editorial Universitaria]. 


\section{Heriberto Cairo}

NICHOLLS, Walter. (2009), "Place, Networks, Space: Theorising the Geographies of Social Movements". Transactions of the Institute of British Geographers, vol. 34, no 1, pp.78-93.

PREVELAKIS, George. (2000), “Networks and Territories in European Geopolitics”. Ponencia en XVIII World Congress of the International Political Science Association, Quebec, Canada.

REYNAUD, Alain. (1982), La Géographie, Science Sociale. Reims, Travaux de l'Institut de Géographie de Reims.

SACK, Robert D. (1986), Human Territoriality: Its Theory and History. Cambridge, Cambridge University Press.

SCHMITT, Carl. (1942), Land und Meer. Eine weltgeschichtliche Betrachtung [trad. al castellano por R. Fernández-Quintanilla (1952), Tierra y mar. Consideraciones de la historia universal. Madrid, Instituto de Estudios Políticos].

SCHMITT, Carl. (1950), Der Nomos der Erde im Völkerrecht des Jus Publicum Europaeum [trad. al castellano por D. Schilling Thou (2002), El Nomos de la Tierra en el Derecho de Gentes del "Ius publicum europaeum". Granada, Comares].

SCHNEIDER, Mark et al. (2003), “Building Consensual Institutions: Networks and the National Estuary Program". American Journal of Political Science, vol. 47, no 1, pp. 143-158.

SHAPIRO, Michael J. (1989), “Textualizing Global Politics”, en J. Der Derian y M. J. Shapiro (eds.), International/ Intertextual Relations: Postmodern Readings of World Politics. New York, Lexington Books, pp. 11-22.

. (2001), For Moral Ambiguity: National Culture and the Politics of the Family. Minneapolis, University of Minnesota Press.

_ y NEAUBAUER, Deanne. (1990), "Spatiality and Policy Discourse: Reading the Global City", en R. B. J. Walker y S. H. Mendlovitz (eds.), Contending Sovereignties: Redefining Political Community. Boulder (Co.), Lynne Rienner, pp. 97-124.

SMITH, Neil. (1992), "Contours of a Spatialized Politics: Homeless Vehicles and the Production of Geographical Scale". Social Text, no 33, pp. 54-81.

SOJA, Edward. (1971), The Political Organization of Space. Washington, Association of American Geographers.

(1980), "The Socio-spatial Dialectic". Annals of the Association of American Geographers, vol. 70, no 2, pp. 207-225.

(1989), Postmodern Geographies: The Reassertion of Space in Critical Social Theory. London, Verso.

TAPIA, Luis. (2009), Pensando la Democracia Geopolíticamente. La Paz, CLACSO/CIDES / Muela del Diablo Editores.

TAYLOR, Peter J. (1984), "Geographical Scale and Political Geography", en P. J. Taylor y J. W. House (eds.), Political Geography: Recent Advances and Future Directions. London, Croom Helm, pp.1-7. 
(1987), "The Poverty of International Comparisons: Some Methodological Lessons from World-systems Analysis". Studies in Comparative International Development, vol. 22, pp.12-39.

TOCQUEVILLE, Alexis de. (1840), La Démocratie en Amérique [ed. y trad. al castellano de D. Negro Pavón (1971), La democracia en América. Madrid, Aguilar].

WALKER, Rob B. J. (1988), "State Sovereignty, Global Civilization and the Rearticulation of Political Space". World Order Studies Program, Occasional Paper, no 18. Center of International Studies, Princeton University.

. (1989), "The Prince and 'The Pauper': Tradition, Modernity, and Practice in the Theory of International Relations", en J. Der Derian y M. J. Shapiro (eds.), International/Intertextual Relations. Postmodern Readings of World Politics. New York, Lexington Books, pp. 25-48.

(1993), Inside/Outside: International Relations as Political Theory. Cambridge, Cambridge University Press.

y MENDLOVITZ, Saul A. (1990), “Interrogating State Sovereignty", en R.B.J. Walker y Saul H. Mendlovitz (eds.), Contending Sovereignties: Redefining Political Community. Boulder, Lynne Rienner, pp.1-12.

WEBER, Max. (1919), Politik als Beruf [trad. al castellano por J. Abellán (2001) La ciencia como profesión. La política como profesión. Madrid, Espasa Calpe (2aed.)].

. (1956), Wirtschaft und Gesellschaft. Grundriss der Verstehenden Soziologie (4a ed.) [trad. al castellano por J. Medina Echevarría, J. Roura Parella, E. García Máynez, E. Ímaz y J. Ferrater Mora (1964), Economía y sociedad. Esbozo de Sociología Comprensiva. México, Fondo de Cultura Económica, 2 vols.]. 


\section{Heriberto Cairo}

\section{ABSTRACT}

Space and Politics: Towards a Situated Political Theory

This article explores three types of relation between space and politics in the modern political theory: one separates both categories, the other identifies them partially and the last one links them closely. The latter shows the connexions between structures, practices and spatial discourses that allow seeing how political facts are always "located", making it impossible to interpret them on the margins of their context of appearance and development. We defend, finally, the development of situated politics.

Key words: space; territory; place; political theory; power

\section{RÉSUMÉ}

\section{Espace et Politique: Pour une Théorie Politique Située}

Cet article explore trois types de relation entre espace et politique dans la théorie politique moderne: l'une sépare les deux catégories, l'autre les identifie partiellement et une dernière les lie étroitement. C'est à partir de celle-ci qu'apparaissent les connexions entre structures, pratiques et discours spatiaux, qui permettent de voir comment les faits politiques se trouvent toujours "placés", devenant impossible de les interpréter en marge de leur contexte d'apparition et de développement. Nous défendons, enfin, le développement d'une politique située.

Mots-clés: espace; territoire; lieu; théorie politique; pouvoir 